\title{
Repair of Furcal latrogenic Perforation with Mineral Trioxide Aggregate: Two Years Follow-up of Two Cases
}

\author{
Gul Celik Unal ${ }^{a}$ \\ Murat Maden ${ }^{a}$ \\ Tugba Isidan ${ }^{a}$
}

\begin{abstract}
Furcal perforation is usually an undesired complication that can occur during preparation of endodontic access cavities or exploring canal orifice of multirooted teeth. Inadequacy of the repair materials has been a contributing factor to the poor outcome of repair procedures. On the basis of the recent physical and biologic property studies of the relatively new introduced mineral trioxide aggregate, this material may be suitable for closing the communication between the pulp chamber and the underlying periodontal tissues. There are few reports on repair of furcal perforation with MTA in molar teeth. The purpose of this case report was to describe the treatment of two furcal perforation using MTA in molar teeth. The perforations were cleaned with $\mathrm{NaOCl}$ and saline solution and sealed with MTA without internal matrix. Finally, the teeth were endodontically treated and coronally restored with composite resin and ceramic veneer crown and bridge. After 2 years, the absence of periradicular radiolucent lesions, pain, and swelling along with functional tooth stability indicated a successful outcome of sealing perforations in two cases. (Eur J Dent 2010;4:475-481)
\end{abstract}

Key words: Repair; latrogenic furcal perforation; MTA; Root canal treatment.

\section{INTRODUCTION}

Mineral trioxide aggregate (MTA) has been regarded as an ideal material for perforation repair, retrograde filling, pulp capping, and apexification since its introduction in 1993.1,2 The principle compounds present in MTA are several mineral

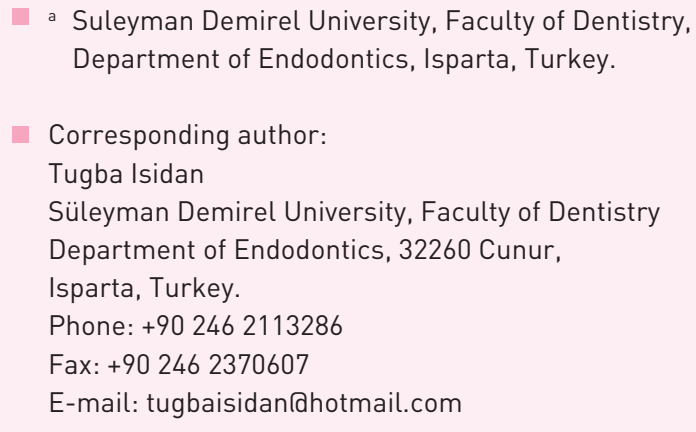


omer cements. ${ }^{8}$ Also the ideal material for treating radicular perforations should be nontoxic, nonabsorbable, radiopaque, and bacteriostatic or bactericidal. ${ }^{11}$ MTA has all of these characteristic and has applied with good outcomes in root-end filling, direct pulpal capping, apexification, repair of furcal perforation and radicular resorption. ${ }^{5}$ Microscopic examinations of periodontal tissues after perforations in the furcal area and subsequent sealing with MTA demonstrated repair of the periodontium, and new cementum formation over the material. ${ }^{12}$ The repair capacity of MTA can in turn be attributed to the antimicrobial properties and high $\mathrm{pH}$ (12.5) of MTA. These characteristic of MTA promote growth of the cementum and formation of bone. ${ }^{13}$

Furcal perforation is usually an undesired complication that can occur during preparation of endodontic access cavities or exploring canal orifice of multirooted teeth. ${ }^{14}$ These undesirable situations such as excess removal of tooth structure or perforation occur during attempts to locate canals or as a direct result of failing to achieve straight line access to the canals. In the process of searching for canal orifices, perforations of the crown can occur, either peripherally through the sides of the crown or through the floor of the chamber into the furcation. ${ }^{15}$ Such perforation are managed surgically or nonsurgically. ${ }^{16}$ Various materials have been used in repairing perforations including zinc oxide-eugenol, amalgam, calcium hydroxide, composite resin, glass ionomer and resin-modified glass ionomer. ${ }^{17}$

There are few reports on repair of furcal perforation with mineral trioxide aggregate (MTA). Arens and Torabinejad ${ }^{18}$ reported that 2 cases are described in which MTA was used to repair furcation perforation successfully. Pace et $\mathrm{al}^{19}$ had done clinical and radiographic follow-ups at 6 months, 1 year, 2 years, and 5 years, and after 5 years, and indicated a successful outcome of sealing perforations in 9 out of 10 teeth. Oliveira et al ${ }^{20}$ had also repaired furcal perforation with MTA in a primary molar tooth, and done follows-up 20 months. They indicated clinical and radiographic success. Silveira et al $^{21}$ reported that 2 cases are described in which MTA was used to repair furcation perforation.

The aim of this long-term follow-up case report is to present a successful treatment of iatrogenic furcal perforation by MTA.

\section{CASE REPORTS}

Case 1

A healthy 50-yr-old man was referred to the Department of Endodontics, Suleyman Demirel University after an initial appointment ten days previously for root canal treatment of tooth 46 . He expressed that the dentist was unable to localize the root canals' orifices.

Clinical examination showed no sensitivity to percussion and palpation test. The mean probing pocket depth was within normal level. The radiographic examination showed a little radiolucent area in furcal region of tooth 46 (Figure 1).

The crown and temporary restorative material was removed and the larger perforation area than the radiographic imagine of the perforation was detected clinically (Figure 2). Hemorrhage was controlled with copious irrigation with $1 \%$ sodium hypochlorite. Blockage was determined in the mesial canals. The working lengths were determined with Raypex 5 (VDW Endodontic Synergy $\mathrm{GmbH}$, Munich, Germanyl. The mesial and distal canals were cleaned and shaped using ProFile ISO files (Dentsply Maillefer, Ballaigues, Switzerland) in a crown-down technique and copious irrigation with $5.25 \%$ sodium hypochlorite. The root canals were then obturated with gutta-percha points and $\mathrm{AH}$ 26 (Dentsply, DeTrey Konstanz, Germany) using the lateral condensation technique. The perforation sealed with mineral trioxide aggregate-sterile saline paste ProRoot MTA (Dental Tulsa; Dentsply, DeTrey Konstanz, Germanyl mixed in a 3:1 proportion. In this appointment, which applied MTA with an amalgam carrier, a cotton pellet was then placed in the pulp chamber to produce a humid ambient for the MTA with the aim of achieving its solidification, and the tooth was temporary filled with Cavit temporary restoration material (Cavit-G, 3M ESPE, St. Paul, Minnesota, USA) (Figures 3 and 4). The patient returned to the clinic three days later with no symptoms or signs. Temporary sealing materials and the wet cotton pellet were removed and the hardness of the MTA was gently tested with an operative explorer. In this appointment, a fiber post (D.T. LIGHT-POST Bisco, Inc. Schamburg, IL, USA) was also applied into the distal canal because of reinforcement and composite resin (FiltekTM Supreme XT, 3M ESPE, St. Paul, Minnesota, USA) (Figure 5). Later, a ceramic veneer was applied.

At the 6-month recall, the tooth remained as- 
ymptomatic. The clinical examinations showed that the tooth had no pain and no response to percussion, palpation and there were no probing depths (Figure 6). A two-year follow-up revealed adequate clinical function. Radiographic findings showed adequate sealing of the perforation region and the tooth had no radiolucency at the furcal area and the apexes (Figure 7).

Case 2

A 59-yr-old female was referred to the Depart-

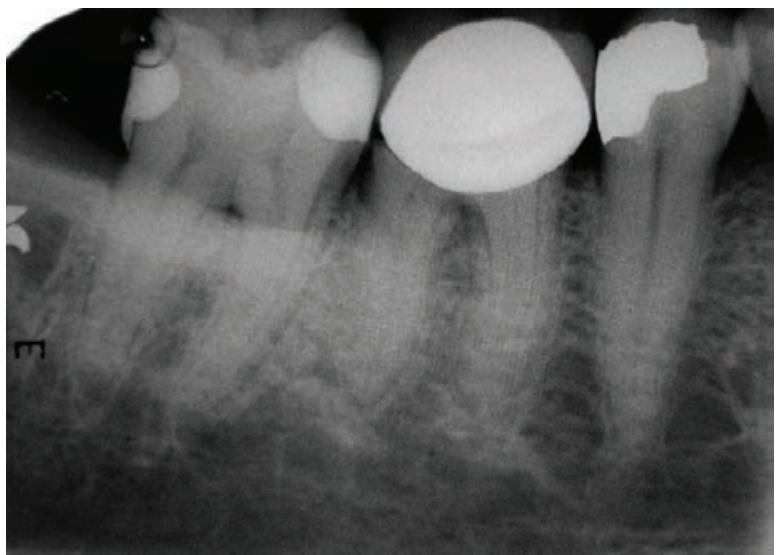

Figure 1. Periapical image of tooth 46 showing little furcal radiolucency (Case 1).

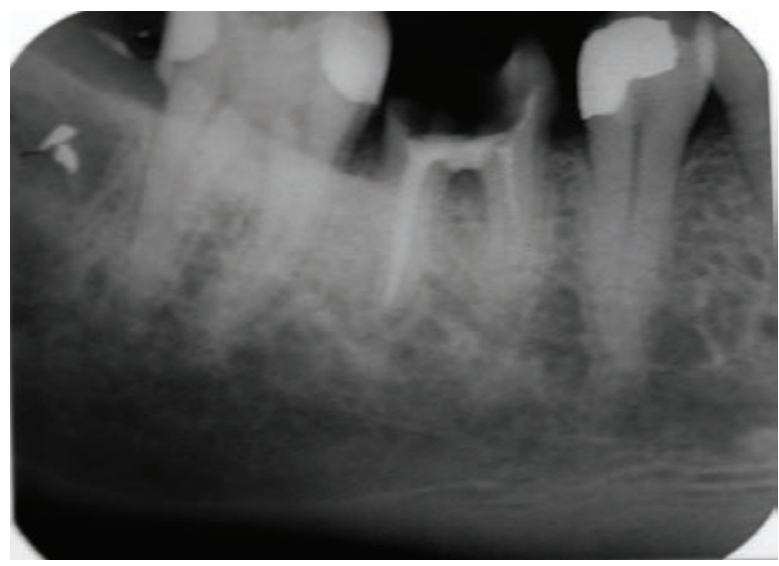

Figure 3. Radiograph after MTA application. Because of the blockage, mesial canals were obturated short (Case 1).

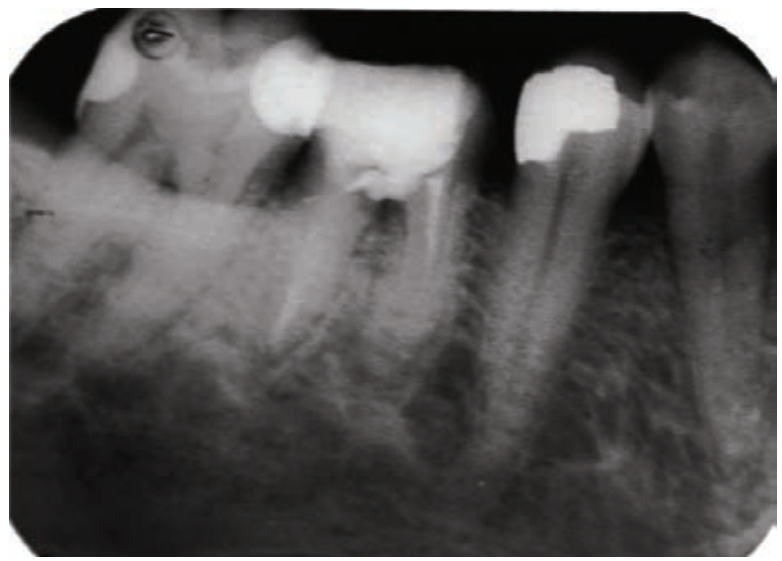

Figure 5. Radiograph after application of fiber post in distal canal and restoration with composite resin (Case 1).

October 2010 - Vol.4 ment of Endodontics, Suleyman Demirel University after an appointment for root canal treatment of the tooth 26 . The patient complained of spontaneous pain in the left maxillary region. The patient declared that she was referred to our clinic 15 days after initial appointment.

Upon clinical examination, the tooth had no tenderness on palpation and no mobility, but had percussion pain. Upon radiographic examination, radiolucency was observed in the furcal region (Figure 8).

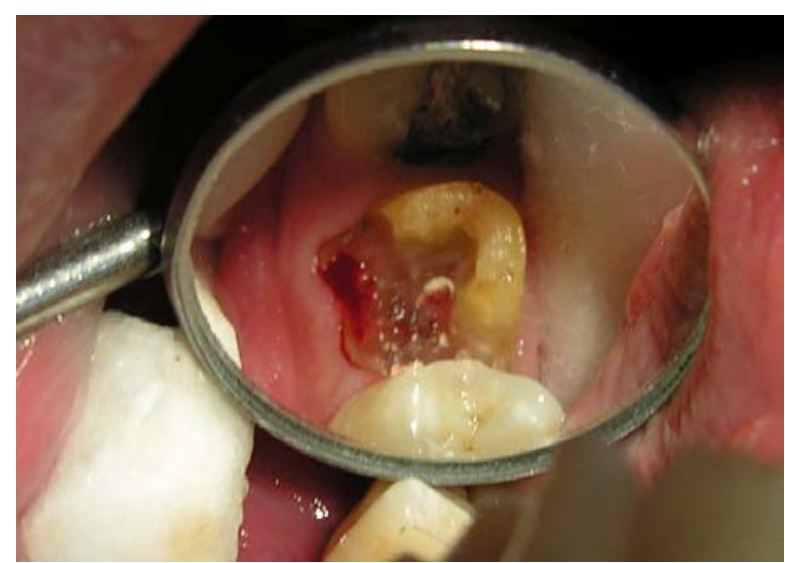

Figure 2. Clinical view of the large furcal perforation.

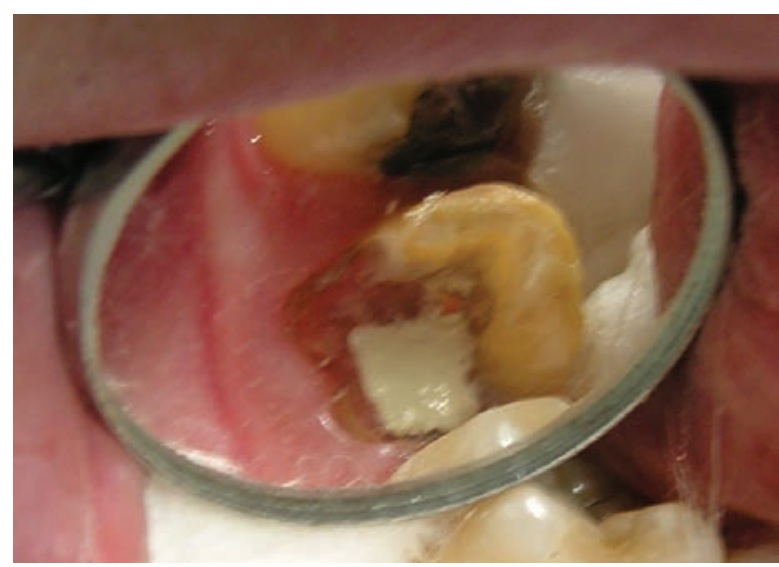

Figure 4. Clinical image of MTA application (Case 1).

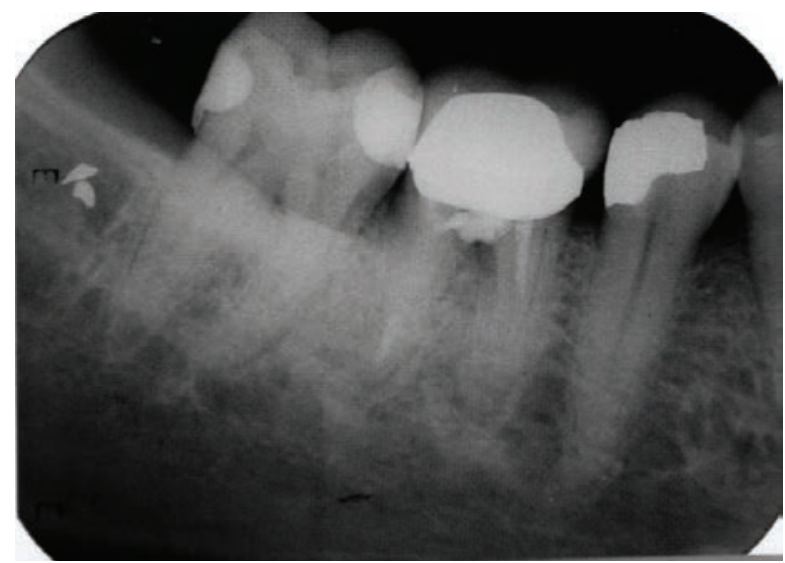

Figure 6. At 6 month follow up, there is osseous healing at furcal area (Case 1). 


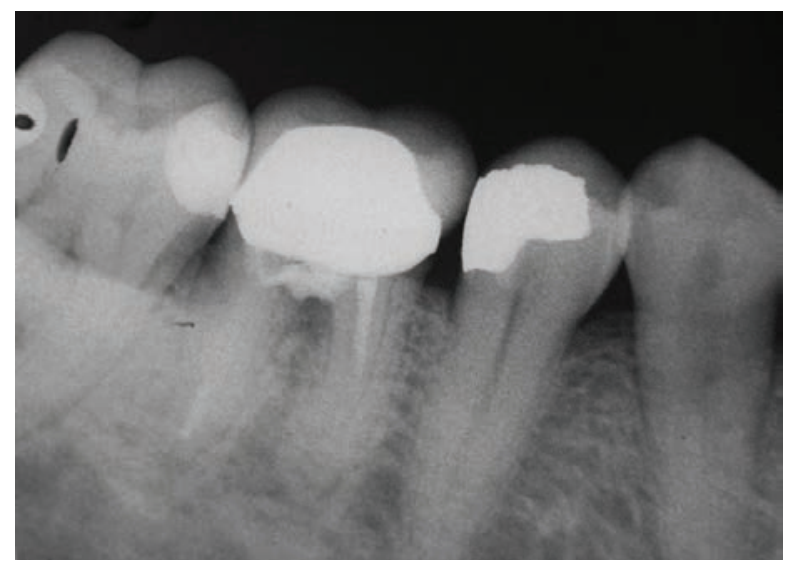

Figure 7. Osseous repair can still be seen at the 2-year follow-up (Case 1).

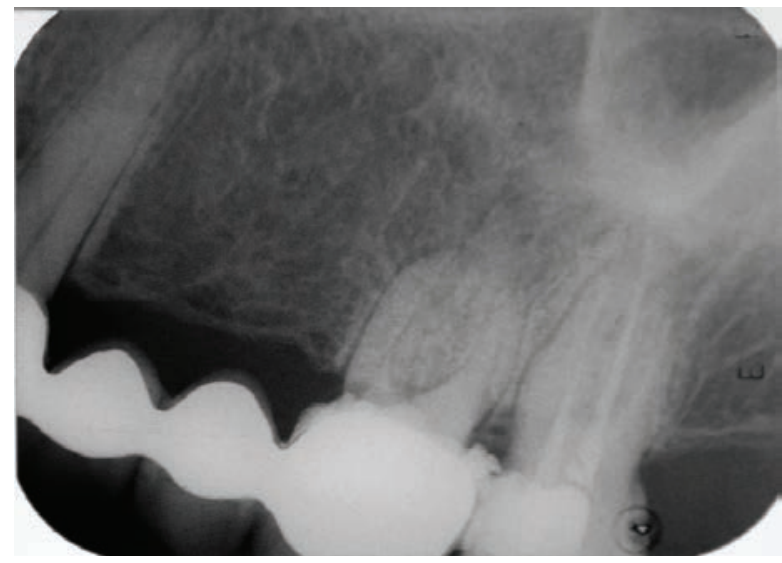

Figure 8. Periapical image of tooth 46 showing little furcal radiolucency (Case 2).

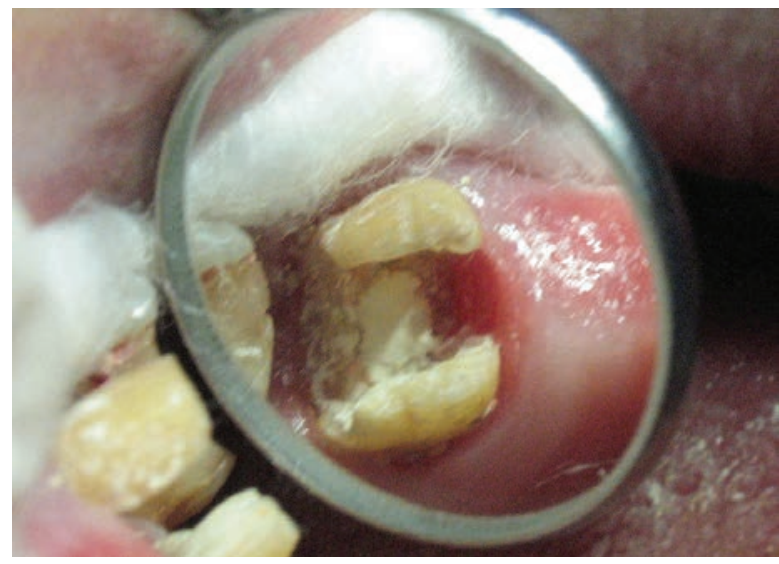

Figure 10. MTA placed with temporary restoration (Case 2).

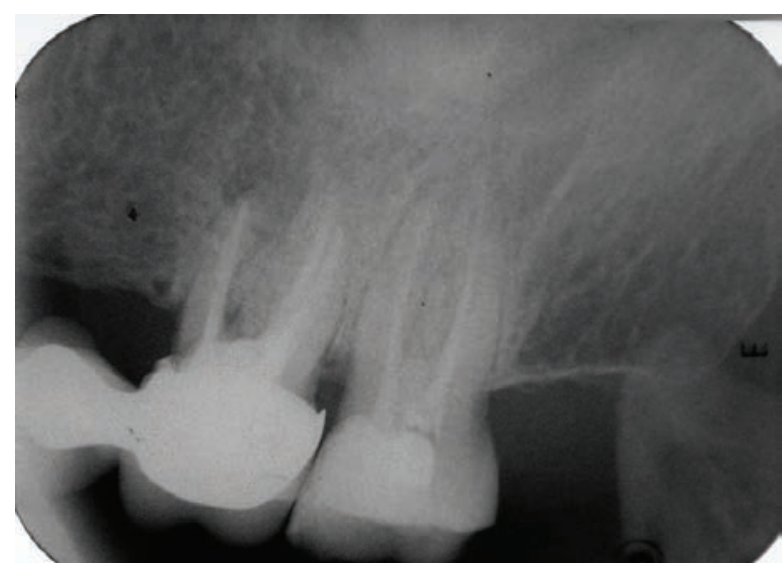

Figure 12. MTA seal and new root canal treatment at 6-month follow-up (Case 2).
The bridge restoration and temporary restorative material were removed. Hemorrhage was controlled with copious irrigation with $1 \%$ sodium hypochlorite. The furcal perforation was confirmed by photograph taken clinically of tooth 26 , which revealed osseous breakdown at the furcation (Figure 9). The obturation of root canals and repairing of perforation with MTA were performed in a similar manner to Case 1 (Figures 10 and 11). A ceramic crown-bridge was then applied between teeth numbers 23-26.

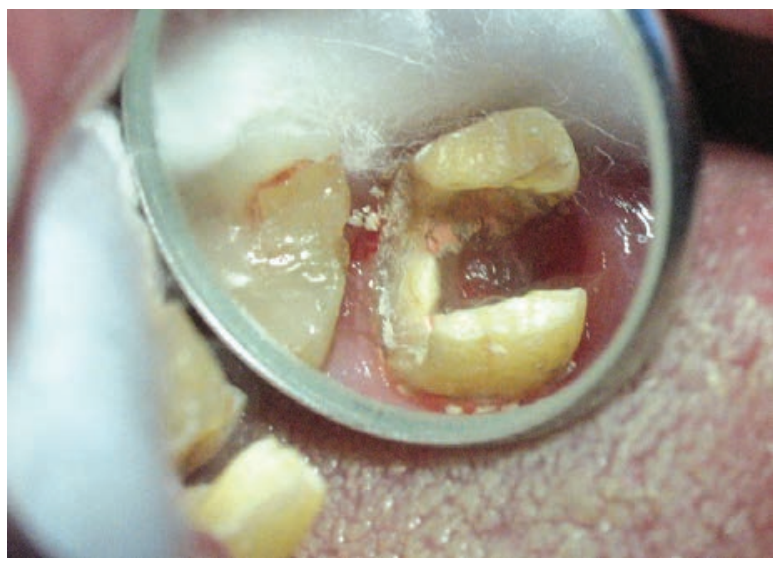

Figure 9. Clinic view of perforation area (Case 2).

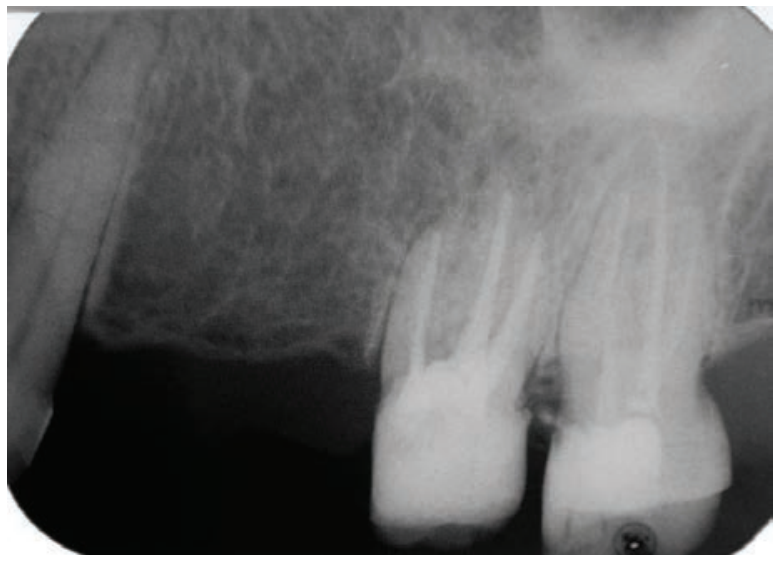

Figure 11. Radiograph after MTA application (Case 2).

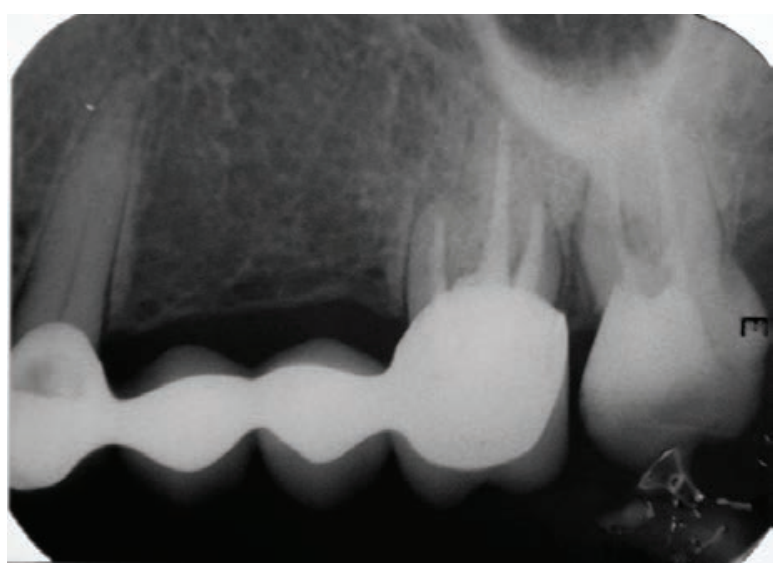

Figure 13. Bone formation is visible at 2-year follow-up (Case 2) 
At the 6-month follow-up, radiographic examination revealed further healing (Figure 12). The patient was asymptomatic. Clinical follow-up at two years revealed adequate clinical function and an absence of clinical symptoms. Radiographic follow-up at two years showed that the furcal radiolucency had disappeared (Figure 13).

\section{DISCUSSION}

In the past years, amalgam, composite resin, and glass ionomer cements have been used for sealing furcal perforation. However, studies have shown that MTA is apparently superior to these materials with respect to marginal adaptation, $3,4,22-24$ bacterial leakage $e^{3,4,22-25}$ and cytotoxicity. ${ }^{3,26}$ Main et a ${ }^{27}$ concluded that MTA provides an effective seal of root perforations and can be considered a potential repair material enhancing the prognosis of perforated teeth that would otherwise be compromised. Economides et a ${ }^{28}$ also reported that MTA is a biocompatible material when used in root-end cavities, stimulating reparation of periradicular tissues, showed no inflammation and deposition of cementum over MTA in the majority of the specimens when placed on root perforations in dog's teeth ${ }^{29}$ and the ability to induce hard tissue formation. ${ }^{30}$ The desirable properties of MTA make it a useful material in repairing the root and furcal perforation.

The prognosis of perforations depends on the location, size and time of contamination of the lesion. ${ }^{17}$ The location of furcal perforations at the level of the epithelial attachment and crestal bone suggested a guarded prognosis. ${ }^{31}$ Secondly, the size of a perforation represents another important factor in determining the success of the repair procedure; some authors suggest the use of internal matrix to avoid the extrusion of the sealing material and consequent periradicular tissue inflammation. ${ }^{32}$ In our cases, furcal perforations were small, with a low risk of filling material extrusion. Finally, interval between perforation and repair is one of the critical factors for success. ${ }^{17,23,33} \mathrm{Imme-}$ diate sealing of perforations enhances the repair process due to reduce the possibility of bacterial contamination of the defect. ${ }^{27}$ Holland et a ${ }^{34}$ shown that the lateral root perforations sealed with MTA after contamination presented worse repair than the noncontaminated, immediately sealed perforations. In the presented cases, al- though the time between perforation and repair was 10 days in Case 1 and two weeks in Case 2, MTA treatment was successful, as indicated by imaging at 6 months and 2 years, respectively. In another study, the time elapsed from the creation of the perforation to repair of the defect did not exceed 6 months and the use of MTA to seal furcal perforation was associated with a good shortterm clinical outcome. ${ }^{19}$

Inadequacy of the repair materials can also be a contributing factor to the poor outcome of repair procedures. Despite an accurate diagnosis and immediate treatment planning, a suitable material is also a key element in successfully sealing perforation. ${ }^{33,35}$ The clinical applications to human subjects also have proved that MTA is good for solving the problems derived from perforationit is not interfered in the presence of moisture and inhibits the activity of bacteria. ${ }^{21}$ However, the option of sealing the perforation immediately provided for an adequate endodontic therapy in the following visit, free of hemorrhage and contamination, which would negatively influence the outcome of the therapy. Nicholls ${ }^{36}$ recommended that contaminated perforations be washed out with hypochlorite. Pitt Ford et al ${ }^{12}$ reported good response in which repair with MTA can likely be attributed to the effective use of hypochlorite irrigation. Perforation areas were washed with hypochlorite and the hemorrhage was stopped in our cases.

Materials used to repair furcal perforations and restore molar teeth must respond to occlusal forces. In recent studies, maximum bite force was found to be $640 \mathrm{~N}$ in all teeth and $265 \mathrm{~N}$ in one tooth. ${ }^{37}$ However, bite force was significantly associated with gender, age, self-rated general health, and occlusal support, but not with temporomandibular junction (TMJ) noise or mouth opening limitation. ${ }^{37}$ For many studies, bite force was found to be $512 \mathrm{~N}$ in men, and 443 in women. 38,39 At $24 \mathrm{~h}$ MTA had the lowest compressive strength (40 MPa) among the amalgam, Super-EBA, and Intermediate Restorative Material (IRM) but it increased after 21 days to $67 \mathrm{MPa}$. MTA should not be placed in functional areas, because it has low compressive strength. ${ }^{40}$ The sites where applied MTA should not receive a direct occlusal load. However, clinical case reports in which MTA has been used to repair furcation perforations with 
both clinical and radiographic success have also been reported at long-time follow-up. ${ }^{18-21,41}$ In presented clinical case reports, the composite was restored coronally after application of MTA and applied veneer porcelain restoration for distribution of occlusal load.

On the basis of these property studies of the mineral trioxide aggregate, we used MTA in our cases and the material resulted in successful repair of perforating furcal perforation at a two-year follow-up. After two years, the teeth remained asymptomatic, radiographic examination showed signs of normality and the patients were satisfied to keep the tooth.

\section{CONCLUSIONS}

MTA has the potential as a material for repair of furcal perforation. However, MTA should be further tested for response to occlusal forces and research about the materials that can be used with MTA should be designed.

\section{REFERENCES}

1. Lee SJ, Monsef M, Torabinejad M. Sealing ability of a mineral trioxide aggregate for repair of lateral root perforations. J Endod 1993;19:541-544.

2. Osorio RM, Hefti A, Vertucci FJ, Shawley AL. Cytotoxicity of endodontic materials. J Endod 1998;24:91-96.

3. Torabinejad M, Hong CU, Lee SJ, Monsef M, Pitt Ford TR. Investigation of mineral trioxide aggregate for root-filling in dogs. J Endod 1995;21:603-608.

4. Torabinejad M, Pitt Ford TR. Root-end filling materials: a review. Endod Dent Traumatol 1996;12:161-178.

5. Torabinejad M, Chivian N. Clinical applications of mineral trioxide aggregate. J Endod 1999;25:197-205.

6. Mc Cabe PS. The clinical applications of mineral trioxide aggregate. J Ir Dent Assoc 2003;49:123-131.

7. Hardy I, Liewehr FR, Joyce AP, Agee K, Pashley DH. Sealing ability of One-Up Bond and MTA with and without a secondary seal as furcation perforation repair materials. $J$ Endod 2004;30:658-661.

8. Daoudi MF, Saunders WP. In vitro evaluation of furcal perforation repair using mineral trioxide aggregate or resin modified glass ionomer cement with and without the use of the operating microscope. J Endod 2002;28:512-515.

9. Nakata TT, Bae KS, Baumgartner JC. Perforation repair comparing mineral trioxide aggregate and amalgam using an anaerobic bacterial leakage model. $J$ Endod 1998;24:184-186.
10. Hashem AAR, Hassanien EE. ProRoot MTA, MTA-Angelus, and IRM used to repair large furcation perforations: sealability study. J Endod 2008;34:512.

11. De-Deus G, Reis C, Brandão C, Fidel S, Fidel RA. The ability of Portland cement, MTA and MTA Bio to prevent throughand-through fluid movement in repaired furcal perforations. J Endod 2007;33:1374-1377.

12. Pitt Ford TR, Torabinejad M, McKendry DJ, Hong CU, Kariyawasam SP. Use of mineral trioxide aggregate for repair of furcal perforations. Oral Surg Oral Med Oral Pathol Oral Radiol Endod 1995;79:756-763.

13. Roberts HW, Toth JM, Berzins DW, Charlton DG Mineral trioxide aggregate material use in endodontic treatment: a review of the literature. Dent Mater 2008;24:149-164.

14. Bargholz C. Perforation repair with mineral trioxide aggregate: a modified matrix concept. Int Endod J 2005;38:59-69.

15. Frank RJ Endodontic mishaps: Their detection, correction, and prevention: Ingle JI, Bakland LK, eds. Endodontics, 5th ed. London, BC Decker Inc 2002;769-794.

16. Roda RS Root perforation repair: surgical and nonsurgical management. Pract Proced Aesthet Dent 2001;13:467-472.

17. Fuss Z, Trope M. Root perforations: classification and treatment choices based on prognostic factors. Endod Dent Traumatol 1996;12:255-264.

18. Arens DE, Torabinejad M. Repair of furcal perforations with mineral trioxide aggregate-two case reports. Oral Surg 1996;82:84-88.

19. Pace R, Giuliani V, Pagavino G. Mineral trioxide aggregate as repair material for furcal perforation: case series. $J$ Endod 2008;34:1130-1133.

20. Oliveira TM, Sakai VT, Silva TC, Santos CF, Machado MA Abdo RC. Repair of furcal perforation treated with mineral trioxide aggregate in a primary molar tooth: 20-month follow-up. J Dent Child (Chic) 2008;75:188-191.

21. Silveira $C M$, Sánchez-Ayala $A$, Lagravère $M O$, Pilatti GL, Gomes OM. Repair of furcal perforation with mineral trioxide aggregate: long-term follow-up of 2 cases. J Can Dent Assoc 2008;74:729-733.

22. Torabinejad M, Pitt Ford TR, McKendry DJ, Abedi HR, Miller A, Kariyawasam SP. Histologic assessment of mineral trioxide aggregate as a root-end filling in monkeys. $J$ Endod 1997;23:225-228.

23. Wu M, Kontakiotis EG, Wesselink PR. Long-term seal provided by some root-end filling materials. I Endod 1998;24:557-560.

24. Shabahang S, Torabinejad M, Boyne PP, Abedi H, McMillan P. A comparative study of root-end induction using osteogenic protein-1, calcium hydroxide and mineral trioxide aggregate in dogs. $J$ Endod 1999;25:1-5. 
25. Bates CF, Carners DL, Del Rio CE. Longitunal sealing ability of MTA as a root-end filling material. J Endod 1996;22:575578.

26. Keiser K, Johnson C, Tipton DA. Cytotoxicity of MTA using human periodontal ligament fibroblasts. $J$ Endod 2000;26:288-289.

27. Main C, Mirzayan N, Shabahang S, Torabinejad M. Repair of root perforations using mineral trioxide aggregate: a longterm study. J Endod 2004;30:80-83.

28. Economides N, Pantelidou O, Kokkas A, Tziafas D. Shortterm periradicular tissue response to mineral trioxide aggregate (MTA) as a root-end filling material. Int Endod $J$ 2003;36:44-48.

29. Holland R, Filho JA, De Souza V, Nery MJ, Bernabe PF, Junior ED. Mineral trioxide aggregate repair of lateral root perforations. J Endod 2001;1:281-284.

30. Yaltirik M, Ozbas H, Bilgic B, Issever H. Reactions of connective tissue to mineral trioxide aggregate and amalgam. J Endod 2004;30:95-99.

31. Tsesis I, Rosen E, Schwartz-Arad D, Fuss Z. Retrospective evaluation of surgical endodontic treatment: traditional versus modern technique. J Endod 2006;32:412-416.

32. Rafter M, Baker M, Alves M, Daniel J, Remeikis N. Evaluation of healing with use of an internal matrix to repair furcation perforations. Int Endod J 2002;35:775-783.

33. Alhadainy HA. Root perforations. Oral Surg Oral Med Oral Pathol Oral Radiol Endod 1994;78:368-374.

34. Holland R, Bisco Ferreira L, de Souza V, Otoboni Filho JA, Murata SS, Dezan E Jr. Reaction of the lateral periodontium of dogs' teeth to contaminated and noncontaminated perforations filled with mineral trioxide aggregate. J Endod 2007;33:1192-1197.

35. Ingle Jl, Simon JH, Machtou P, Bogaerts P. Outcome of endodontic treatment and retreatment. In: Ingle JI, Bakland LK, eds. Endodontics, 5th ed. London, BC Decker Inc., 2002; p. 753-755.

36. Nicholls E. Treatment of traumatic perforations of the pulp cavity. Oral Surg Oral Med Oral Pathol 1962;15:603-612.

37. Ikebe K, Nokubi T, Morii K, Kashiwagi J, Furuya M. Association of bite force with ageing and occlusal support in older adults. J Dent 2005;33:131-137.

38. Miyaura K, Matsuka Y, Morita M, Yamashita A, Watanabe T. Comparison of biting forces in different age and sex groups: a study of biting efficiency with mobile and nonmobile teeth. J Oral Rehabil 1999;26:223-227.

39. Yamashita S, Sakai S, Hatch JP, Rugh JD. Relationship between oral function and occlusal support in denture wearers. J Oral Rehabil 2000;27:881-886.
40. Torabinejad M, Hong CU, McDonald F, Pitt Ford TR. Physical and chemical properties of a new root-end filling material. J Endod 1995;21:349-353.

41. Bargholz C. Perforation repair with mineral trioxide aggregate: A modified matrix concept. Int Endod J 2005;38:59-69. 